\title{
Association between diet and gallstones of (cossmak cholesterol and pigment among patients with cholecystectomy: a case-control study in Korea
}

Yongsoon Park ${ }^{1 *+}$ D, Doyeon Kim¹, Ju Seon Lee ${ }^{1}$, Yu Na Kim¹, Yoon Kyung Jeong², Kyeong Geun Lee ${ }^{2}$ and Dongho $\mathrm{Choi}^{2+}$

\begin{abstract}
Background: The prevalence of cholesterol gallstones is high in Western populations, while pigment gallstones are common in Asian populations. Dietary factors are suggested to be associated with gallstone risk, but their relationship with gallstone type has not been evaluated. This study investigated the association between diet and risk of cholesterol gallstone or pigment gallstone in a Korean population whose dietary pattern and type of gallstone were changed during the last 30 years.

Methods: Patients with cholesterol $(n=40)$ and pigment $(n=59)$ gallstones were recruited after laparoscopic cholecystectomy and were compared with those of age- and sex-matched controls without gallstones $(n=99)$. Dietary intakes were assessed by trained dietitians using a semi-quantitative food frequency questionnaire. Multinomial logistic regression analysis was performed to calculate odds ratios and $95 \%$ confidence intervals to examine the associations between diet and risk for type of gallstones adjusted by potential confounders.

Results: Patients with cholesterol gallstone consumed more lipid, animal lipid, beef, pork, and fried food than those with pigment gallstones and control, while patients with pigment gallstone consumed more carbohydrate and noodles than patients with cholesterol gallstone and control. In multinomial logistic regression analysis using control as reference group, dietary pattern with high consumption of beef, pork, and fried food was associated with risk of cholesterol gallstones, while there was no association between the risk of pigment gallstone and dietary pattern. In addition, control consumed more alcohol than patients with cholesterol and pigment gallstones.
\end{abstract}

Conclusions: The present study suggested consumption of fat from meat and fried foods increased the risk of cholesterol gallstone, and intake of carbohydrate from noodles increased the risk of pigment gallstone.

Keywords: Cholesterol gallstone, Pigment gallstone, Cholecystectomy, Diet, Korean

\footnotetext{
* Correspondence: yongsoon@hanyang.ac.kr

${ }^{\dagger}$ Equal contributors

${ }^{1}$ Department of Food and Nutrition, Hanyang University, 222 Wangsimni-ro,

Seongdong-gu, Seoul 04763, South Korea

Full list of author information is available at the end of the article
} 


\section{Background}

Gallstone disease is one of the most prevalent gastrointestinal disorders [1]. Its incidence has increased around the world, including in Korea, over the past 30 years [2]. Gallstones are mostly classified as cholesterol and pigment gallstones; the prevalence of cholesterol gallstones is higher and the prevalence of pigment gallstones is lower in Western populations compared to Asian populations [3]. Development of cholesterol gallstones is related to saturation of cholesterol in bile, cholesterol crystallization and gallbladder stasis [4]. On the other hand, pigment gallstones develop from the release of $\beta$-glucuronidase from bacterial infections; this produces calcium salts of unconjugated bilirubin [5].

It has been shown that age, sex, ethnicity, obesity, and family history of gallstone disease are risk factors for gallstone, and diet is a major modifiable risk factor [1]. Previous studies reported that risk of gallstone was positively associated with intake of meat, energy, fat and saturated fat, but negatively associated with intake of vegetable and fiber in Western and Asian population [6-15]. In particular, high meat intake was associated with risk of gallstone disease [6], since consumption of red meat inhibited bile acid transporters by trimethylamine which induced cholesterol gallstone [16]. In addition, previously studies reported that risk of gallstone was positively intake of margarine, cooking oil, trans fatty acids, and refined sugars, but negatively associated with moderate intake of alcohol and coffee in Western population and Japanese [7, 13, 17-19]. The risk of gallstone was also negatively associated with a healthy dietary pattern in Iranian women [20] and a traditional Mexican diet pattern in MexicanAmerican men [21]. However, none of the above studies differentiated type of gallstones.

A few animal studies reported that intake of high carbohydrate led to formation of pigment gallstone in prairie dogs [22] and hamsters [23]. However, there has been no human study to compared diet and the risk of pigment gallstones.

Pigment gallstones were predominant in Korean people, but the proportion of cholesterol gallstones has been increased $>50 \%$ since the late 1990s [24]. The dietary pattern in Korea has become more westernized with more fat and less fiber during the past a few decades [25]. With the change in dietary pattern, the incidence of cholesterol gallstones has increased and pigment gallstones have decreased in Korea [26]. This finding suggests that Koreans may be a good representative population for analyzing the association between diet and gallstone type. Thus, the purpose of present study was to investigate the hypothesis that westernized diet with more meat rich in fat and less fiber was associated with risk of cholesterol gallstones, while carbohydrate rich diet was associated with risk of pigment gallstones.

\section{Methods}

\section{Subjects}

This study was performed from April 2014 to May 2015 at the general surgery clinic, HYU Hospital, Seoul, Korea with gallstone patients $(n=135)$ who underwent laparoscopic cholecystectomy after diagnosed with gallstones. The presence of gallstones was determined by ultrasonography or computed tomography. Removed gallstones were classified into cholesterol gallstone $(n=40)$, pigment gallstone $(n=59)$, and mixed gallstone $(n=36)$ based on external appearance of the gallstone determined by two independent general surgeons. Patients (cases) were excluded if they had following conditions: underwent open cholecystectomy or biliary drainage procedure; serious comorbidity that required long-term hospitalization; and diagnosed mixed gallstones. Ageand sex-matched controls $(n=99)$ with similar demographic characteristics but without gallstones were recruited from same hospital.

This study protocol was conducted according to the guidelines laid out in the Declaration of Helsinki and was approved by the Institutional Review Board of HYU (HYI-14-001-2). Written informed consent was obtained from all participants.

\section{Demographic data}

Information obtained from participants by trained interviewers included age, sex, family history, medical history, regular exercise, smoking, drinking, and taking supplements. Height and weight were obtained from medical records and body mass index (BMI) was calculated. All women were asked about parity, oral contraceptive use, and hormone replacement therapy.

\section{Dietary assessment}

Dietary intake was assessed by registered dietitian using a semi-quantitative food frequency questionnaire (FFQ) of 63 food items commonly consumed by Koreans Health and Nutrition Examination Survey [27]. Frequency of food intake was classified into 10 categories: one, two, or three times per day; four to six times per week; two to three times per week; once per week; two to three times per month; once per month; six to 11 times per year; never or seldom. Dietary intake was analyzed with CAN-pro 4.0 software (Computer Aided Nutritional Analysis Program for professionals, Korean Nutrition Society, Seoul, Korea).

\section{Statistical analysis}

Data were expressed as mean $\pm \mathrm{SD}$ and a $P$ value $<0.05$ was considered statistically significant. All data were analyzed using SPSS version 21.0 (Statistical Package for Social Science, Inc., Chicago, IL, USA). Categorical variables were analyzed using chi-square test, and 
continuous variables were analyzed using ANOVA after adjusting for potential confounders.

Principal component factor analysis was used to generate dietary patterns based on 25 food groups. Factor scores were rotated using orthogonal (varimax) rotation. To identify the characteristics of the factors, the collection of food groups with factor loadings $>0.4$ was used. The factor score for each pattern was calculated by summing intake of food by their factor loadings [28]. After obtained factor scores, multinomial logistic regression analysis was performed to calculate odds ratios (ORs) and 95\% confidence intervals (CIs) to examine the associations between dietary patterns and risk for cholesterol and pigment gallstones after adjusting for potential confounders such as energy intake, family history of gallstone disease, and drinking, which were significantly different factors among three groups. In addition, energy intake was added as potential confounders for analyzing association between risk of gallstone and intake of nutrients and foods [29].

\section{Results}

Baseline characteristics of subjects

Patients with cholesterol and pigment gallstones had significantly higher family history of gallstone disease as compared to controls, while controls consumed more alcohol than patients with cholesterol and pigment gallstones (Table 1). However, there were no significantly differences in age, sex, pregnancy experience, oral contraceptive use, hormone replacement therapy, height, weight, body mass index (BMI), medical history, exercise, smoking, and supplement use among three groups.

\section{Nutrient and food intake of participants}

Patients with cholesterol gallstone consumed significantly higher fat, animal fat, beef, pork, and fried food

Table 1 Characteristics of controls and patients with cholesterol and pigment gallstones

\begin{tabular}{|c|c|c|c|c|}
\hline & $\begin{array}{l}\text { Controls } \\
(n=99)\end{array}$ & $\begin{array}{l}\text { Cholesterol gallstone } \\
(n=40)\end{array}$ & $\begin{array}{l}\text { Pigment gallstone } \\
(n=59)\end{array}$ & $P$ value ${ }^{d}$ \\
\hline Age (year) & $49.49 \pm 14.79$ & $45.98 \pm 14.92$ & $52.00 \pm 15.70$ & 0.152 \\
\hline Female, $n(\%)$ & $55(55.6)$ & $25(62.5)$ & $33(55.9)$ & 0.739 \\
\hline Experience of pregnancy, $n(\%)$ & $46(83.6)$ & $20(80.0)$ & $27(84.4)$ & 0.897 \\
\hline Contraceptive use, $n$ (\%) & $20(36.4)$ & $6(24.0)$ & $12(37.5)$ & 0.490 \\
\hline Hormone replacement therapy, n (\%) & $11(20.0)$ & $5(20.0)$ & $5(15.6)$ & 0.866 \\
\hline Height (cm) & $163.94 \pm 8.57$ & $163.94 \pm 8.55$ & $163.81 \pm 8.93$ & 0.996 \\
\hline Weight (kg) & $63.65 \pm 10.98$ & $64.28 \pm 9.31$ & $66.13 \pm 13.09$ & 0.411 \\
\hline Body mass index $\left(\mathrm{kg} / \mathrm{m}^{2}\right)$ & $23.58 \pm 2.88$ & $23.87 \pm 2.64$ & $24.51 \pm 3.56$ & 0.181 \\
\hline$<18.5 \mathrm{~kg} / \mathrm{m}^{2}, n(\%)$ & $1(1.0)$ & $1(2.5)$ & $1(1.7)$ & \\
\hline $18.5-22.9 \mathrm{~kg} / \mathrm{m}^{2}, n(\%)$ & $38(38.4)$ & $12(30.0)$ & $18(30.5)$ & 0.746 \\
\hline $23.0-24.9 \mathrm{~kg} / \mathrm{m}^{2}, n(\%)$ & $28(28.4)$ & $13(32.5)$ & $14(23.7)$ & \\
\hline$\geq 25 \mathrm{~kg} / \mathrm{m}^{2}, n(\%)$ & $32(32.3)$ & $14(35.0)$ & $26(44.1)$ & \\
\hline Family history of gallstone disease, $n$ (\%) & $1(1.0)$ & $5(12.5)$ & $7(11.9)$ & 0.007 \\
\hline Medical history, n (\%) ${ }^{a}$ & $55(55.6)$ & $22(55.0)$ & $42(71.2)$ & 0.116 \\
\hline Regular exercise, $n(\%)^{b}$ & $34(34.4)$ & $14(35.0)$ & $18(30.5)$ & 0.858 \\
\hline Smoking, $n(\%)$ & & & & 0.376 \\
\hline Never smoker & $66(66.7)$ & $24(60.0)$ & $32(54.2)$ & \\
\hline Ex-smoker & $16(16.2)$ & $11(27.5)$ & $15(25.4)$ & \\
\hline Current smoker & $17(17.2)$ & $5(12.5)$ & $12(20.3)$ & \\
\hline Drinking, $n(\%)$ & & & & 0.002 \\
\hline Never drinker & $19(19.2)$ & $8(20.0)$ & $17(28.8)$ & \\
\hline Ex-drinker & $4(4.0)$ & $7(17.5)$ & $13(22.0)$ & \\
\hline Current drinker & $76(76.8)$ & $25(62.5)$ & $29(49.2)$ & \\
\hline Use of supplements, $n(\%)^{c}$ & $63(63.6)$ & $29(72.5)$ & $37(62.7)$ & 0.547 \\
\hline
\end{tabular}

Data are mean \pm SD or number of subjects (percentage distribution) as appropriate

${ }^{a}$ Medical history such as diabetes mellitus, cardio-cerebrovascular disease, digestive system disease, respiratory disease, urinary disease, and women's disease

${ }^{\mathrm{b}}$ Regular exercise was defined as three times a week for $\geq 30 \mathrm{~min}$

'Supplements such as vitamins, minerals, n-3 fatty acids, ginseng, and plant extracts

${ }^{\mathrm{d}} P$ value was comparison among three groups by ANOVA for continuous variables or chi-square test for categorical variables 
than patients with pigment gallstone and controls, while patients with pigment gallstone consumed significantly higher carbohydrate and noodles than patients with cholesterol gallstone and controls (Table 2). Control consumed significantly higher alcohol than patients with cholesterol and pigment gallstones. There was no significantly difference on the intake of other nutrients and food among three groups (Additional file 1).

The factor loading matrix for four major factors was determined to eigenvalues $>1.4$ using Scree plot (Additional file 2). Factor 1 reflected high intake of beef, pork, and fried food; factor 2 reflected high intake of white rice, whole grain, vegetable, and legume; factor 3 reflected high intake of tomato, fruit, and mushroom; and factor 4 reflected high intake of egg, poultry, and seafood (Table 3).

In multinomial regression analysis using controls as reference group, the risk of cholesterol gallstone was associated with factor 1 (beef, pork, and fried food), but the risk of pigment gallstones was no associated with specific dietary patterns (Table 4).

\section{Discussion}

The present study showed that patients with cholesterol gallstone consumed significantly higher fat, animal fat, beef, pork, and fried food, while patients with pigment gallstone consumed significantly higher carbohydrate and noodles. In addition, risk of cholesterol gallstone was associated with dietary pattern consuming beef, pork, and fried food, while there was no association between risk of pigment gallstone and dietary pattern.

There has been no study that differentiated cholesterol and pigment gallstones in relation to diet. Previous studies reported that the risk of gallstone was positively associated with intake of meat [6], fat, and saturated fat in Europeans [7, 8, 13, 19]. Meat, a major source of fat and saturated fat, was positively associated with risk of gallstones, while unsaturated fatty acid was negatively associated [7]. Type of gallstones was not determined in the above studies; it was assumed mostly cholesterol gallstones since cholesterol gallstone was common in European [6-10, 12-14, 17-19]. The present study consistently showed that consumption of meat from beef and pork, and animal fat was positively associated with the risk of cholesterol gallstone. With intestinal microbiota, dietary L-carnitine and trimethylamine abundant in red meat produce trimethylamine $\mathrm{N}$-oxide which may induce cholesterol gallstone formation due to inhibited bile acid transporters in hepatocytes [16]. In addition, intake of meat rich in saturated fatty acids decreased insulin sensitivity [30] and caused gallbladder disease and gallbladder dysmotility [31]. Insulin resistance has been shown as a risk factor for cholesterol gallstone [32]. Hyperinsulinemia could increase the activity of HMGCoA reductase, the rate limiting enzyme in hepatic synthesis of cholesterol [33], cholesterol saturation index in the bile [34], thus induce cholesterol gallstone formation. Intake of trans fatty acids from margarine and cooking oil used in frying food has also been suggested to associate with the risk of cholesterol gallstone in American men [17]. Dietary trans fatty acids significantly increase plasma triglyceride levels [35] and impair gallbladder motility from reduced gallbladder sensitivity to cholecystokinin [36]. These findings suggested that hypertriglyceridemia induced by intake of trans fatty acids increased the risk of cholesterol gallstone.

Table 2 Intake of nutrients and foods in controls and patients with cholesterol and pigment gallstones

\begin{tabular}{|c|c|c|c|c|}
\hline & $\begin{array}{l}\text { Controls } \\
(n=99)\end{array}$ & $\begin{array}{l}\text { Cholesterol gallstone } \\
(n=40)\end{array}$ & $\begin{array}{l}\text { Pigment gallstone } \\
(n=59)\end{array}$ & $P$ value \\
\hline Energy (KJ) & $8934.34 \pm 2868.10$ & $9271.01 \pm 3179.46$ & $9390.97 \pm 3413.54$ & 0.575 \\
\hline Carbohydrates (g) & $315.46 \pm 96.03 a$ & $313.18 \pm 96.03^{\mathrm{a}}$ & $340.49 \pm 108.01^{b}$ & 0.029 \\
\hline Lipids (g) & $56.50 \pm 28.63 a$ & $65.81 \pm 35.43^{b}$ & $58.66 \pm 31.62^{a}$ & 0.038 \\
\hline Plant lipid (g) & $26.53 \pm 13.13$ & $29.17 \pm 14.14$ & $29.51 \pm 14.68$ & 0.458 \\
\hline Animal lipid (g) & $29.97 \pm 18.31 a$ & $36.64 \pm 24.47^{b}$ & $29.16 \pm 18.86^{\mathrm{a}}$ & 0.010 \\
\hline Protein (g) & $83.17 \pm 33.29$ & $91.19 \pm 37.79$ & $86.79 \pm 38.34$ & 0.158 \\
\hline Plant protein (g) & $40.57 \pm 13.30$ & $40.97 \pm 12.44$ & $43.91 \pm 15.88$ & 0.144 \\
\hline Animal protein (g) & $42.60 \pm 23.75$ & $50.22 \pm 30.07$ & $42.88 \pm 25.89$ & 0.052 \\
\hline Noodle (frequency/week) & $1.81 \pm 2.59^{\mathrm{a}}$ & $2.41 \pm 2.41^{a, b}$ & $3.13 \pm 3.92^{b}$ & 0.046 \\
\hline Beef (frequency/week) & $1.98 \pm 1.96^{\mathrm{a}}$ & $3.38 \pm 3.16^{b}$ & $2.09 \pm 2.33^{\mathrm{a}}$ & 0.001 \\
\hline Pork (frequency/week) & $2.14 \pm 2.29^{a}$ & $3.25 \pm 3.23^{b}$ & $1.93 \pm 2.04^{\mathrm{a}}$ & 0.012 \\
\hline Fried food (frequency/week) & $0.68 \pm 1.13^{\mathrm{a}}$ & $1.88 \pm 2.72^{b}$ & $0.83 \pm 1.63^{\mathrm{a}}$ & 0.001 \\
\hline Alcohol (frequency/week) & $8.25 \pm 15.48^{\mathrm{a}}$ & $4.49 \pm 12.94^{b}$ & $2.85 \pm 7.49^{b}$ & 0.004 \\
\hline
\end{tabular}

Data are mean \pm SD; values with different letters in the same row are significantly different at $P<0.05$ by ANCOVA after adjusting for energy intake, family history of gallstone disease, and drinking 
Table 3 Rotated-factor loading matrix for the four major

\begin{tabular}{|c|c|c|c|c|}
\hline \multirow[t]{2}{*}{ Variable } & \multicolumn{4}{|c|}{ Factor loading $^{\text {a }}$} \\
\hline & 1 & 2 & 3 & 4 \\
\hline Beef & 0.859 & 0.041 & -0.016 & -0.018 \\
\hline Pork & 0.849 & -0.027 & -0.024 & 0.077 \\
\hline Fried food & 0.799 & -0.079 & -0.038 & 0.058 \\
\hline White rice & -0.015 & 0.791 & -0.079 & -0.125 \\
\hline Whole grain & 0.031 & 0.704 & -0.105 & -0.138 \\
\hline Vegetable & -0.158 & 0.623 & 0.391 & 0.156 \\
\hline Legume & 0.039 & 0.435 & -0.020 & 0.405 \\
\hline Tomato & -0.052 & 0.042 & 0.745 & 0.036 \\
\hline Fruit & -0.004 & -0.068 & 0.659 & 0.066 \\
\hline Mushroom & 0.017 & -0.050 & 0.617 & -0.120 \\
\hline Egg & -0.022 & -0.060 & 0.027 & 0.802 \\
\hline Poultry & 0.399 & -0.167 & 0.015 & 0.514 \\
\hline Seafood & 0.229 & 0.086 & 0.309 & 0.490 \\
\hline Hamburger and pizza & 0.181 & -0.007 & -0.029 & -0.041 \\
\hline Coffee and green tea & -0.037 & -0.088 & -0.023 & 0.028 \\
\hline Processed meat & 0.337 & -0.070 & -0.079 & 0.400 \\
\hline Bread & 0.363 & -0.425 & 0.112 & -0.009 \\
\hline Cracker & 0.043 & -0.074 & 0.041 & 0.120 \\
\hline Noodle & 0.127 & -0.057 & -0.162 & -0.015 \\
\hline Dairy product & -0.012 & -0.107 & 0.035 & -0.029 \\
\hline Rice cake & -0.037 & -0.090 & -0.108 & 0.221 \\
\hline Sweet potato & -0.074 & -0.127 & -0.034 & 0.033 \\
\hline Seaweed & -0.007 & 0.354 & 0.223 & 0.209 \\
\hline Alcohol & 0.038 & 0.018 & -0.145 & 0.033 \\
\hline Carbonated drink & 0.019 & -0.100 & -0.027 & -0.065 \\
\hline Eigenvalue $^{b}$ & 3.668 & 2.230 & 2.022 & 1.467 \\
\hline
\end{tabular}

${ }^{\mathrm{a}}$ Factor loading over 0.4

${ }^{\mathrm{b}}$ Eigenvalues over 1.4 were extracted

A few studies have investigated dietary pattern and gallstone without differentiating gallstone types. In Iranian women, the risk of gallstones was positively associated with the unhealthy dietary pattern including high intake of red and processed meats, high-fat dairy products, eggs, solid fats, snacks, baked potatoes, and refined grains [20]. The present study also showed that the risk of cholesterol gallstone was positively associated with the dietary pattern including high beef, pork, and fried food. One the other hand, the healthy dietary pattern including high intake of vegetables, fruits, low-fat dairy products, vegetable oil, nuts, whole grains, legumes, fruit juice, and fish was negatively associated with the risk of gallstone [20]. Tseng et al. [21] reported that a traditional Mexican diet with high consumption of corn tortillas, chili peppers, and beans was inversely associated with gallstone in Mexican-American men.

Previous studies showed that intake of vegetables and fiber $[9,10,12,13]$ was negatively associated with risk of gallstone formation in Western populations, suggesting that a diet rich in vegetable fiber has a protective effect against gallstone disease. Marcus et al. [37] reported that intake of insoluble fiber decreased intestinal transit time, reduced the biliary deoxycholic acid, and decreased cholesterol saturation index. However, fiber intake was not associated with risk of cholesterol and pigment gallstone in the present study. This discrepancy could be due to that previous study compared fiber intake of gallstone but the present study differentiated type of gallstone. In addition, fiber intake of Korean ( $24 \mathrm{~g} /$ day) was higher than population of above studies. Risk of gallstone was negatively associated with dietary fiber in American women whose average intake was $7.5 \mathrm{~g} /$ day [38], but not associated with dietary fiber in European population whose intake was $22-32 \mathrm{~g} /$ day [6], similar to the fiber intake of dietary fiber in the present study.

Pigment gallstones are suggested to be related to poor hygiene and environmental conditions, but not dietary factors [39]. However, few animal studies reported the association between carbohydrate intake and pigment gallstone. A carbohydrate-rich diet increased biliary concentration of phospholipids, calcium, and bilirubin, leading to formation of bilirubinate crystals in prairie dogs [22]. Lee et al. [23] also showed that a high carbohydrate diet increased the incidence of pigment gallstones in Syrian golden hamsters, suggesting that carbohydrates are a relatively weak stimulator of cholecystokinin. On the other hand, previous studies have consistently reported that intake of refined sugars was positively

Table 4 Association between the risk for cholesterol and pigment gallstones and dietary pattern

\begin{tabular}{|c|c|c|c|c|c|c|c|}
\hline \multirow[t]{2}{*}{ Factor number } & \multirow{2}{*}{$\begin{array}{l}\text { Controls } \\
\text { OR }\end{array}$} & \multicolumn{3}{|c|}{ Cholesterol gallstone } & \multicolumn{3}{|c|}{ Pigment gallstone } \\
\hline & & OR & $95 \% \mathrm{Cl}$ & $P$ value & OR & $95 \% \mathrm{Cl}$ & $P$ value \\
\hline Factor 1 (beef, pork, and fried food) & 1 & 1.737 & $1.11-2.73$ & 0.016 & 0.965 & $0.56-1.68$ & 0.900 \\
\hline Factor 2 (white rice, whole grain, vegetable, and legume) & 1 & 0.646 & $0.38-1.09$ & 0.102 & 0.958 & $0.63-1.47$ & 0.844 \\
\hline Factor 3 (tomato, fruit, and mushroom) & 1 & 0.771 & $0.43-1.39$ & 0.388 & 1.104 & $0.73-1.68$ & 0.643 \\
\hline Factor 4 (egg, poultry, and seafood) & 1 & 0.792 & $0.47-1.35$ & 0.388 & 0.996 & $0.66-1.50$ & 0.983 \\
\hline
\end{tabular}

$O R$ odds ratio, $C l$ confidence interval

$P$ value was compared to the controls by multinomial logistic regression after adjusting for energy intake, family history of gallstone disease, and drinking 
associated with risk of gallstone in Europeans [7, 13, 18]. A diet rich in refined sugar increase insulin, hepatic cholesterol synthesis, and bile cholesterol saturation and impair gallbladder motility, resulting in an increase of gallstone formation [40]. In the present study, intake of carbohydrates was positively associated with risk of pigment gallstone; however, intake of refined sugars was not analyzed due to unavailable data.

Previous studies reported that moderate alcohol consumption was negatively associated with risk of gallstone in European population $[18,41]$ and the protective effect of alcohol against gallstone regardless of the type of alcohol [42]. Consumption of alcohol has been shown to stimulate cholecystokinin release [43], increased intestine motility [44] and plasma level of HDL-cholesterol [45], leading to prevention of biliary stasis and reduction of bile cholesterol saturation [46]. The present study consistently showed that controls consumed more alcohol than cholesterol and pigment gallstones.

A meta-analysis [47] showed that consumption of coffee, particularly caffeinated coffee was positively associated with risk of gallstone disease in Western population, since intake of coffee could have protective effect by stimulating for the secretion of cholecystokinin, leading to increased gallbladder motility [48]. However, intake of coffee or green tea was not associated with risk of gallstone in Japanese [49]. The present study also shows no association between coffee and tea consumption and risk of gallstone.

This study has a few limitations. First, the sample size was small, which could limit the statistical power to detect differences in the diet. Second, adjustment for potential confounding factors could not eliminate the possibility of residual confounding. Third, in the factor analysis, the number of extracted factors and choice of rotation method was subjective.

\section{Conclusions}

In conclusion, our data suggest that intake of red meat from beef and pork, and animal lipid was positively associated with risk of cholesterol gallstone, while intake of carbohydrate and noodles was positively associated with risk of pigment gallstones, suggesting diet influenced the type of gallstone formation.

\section{Additional files}

Additional file 1: Intake of nutrients and foods in controls and patients with cholesterol and pigment gallstones. (DOC $66 \mathrm{~kb}$ )

Additional file 2: Scree plot. (DOC $69 \mathrm{~kb}$ )

\section{Abbreviations}

ANCOVA: Analysis of covariance; ANOVA: Analysis of variance; BMI: Body mass index; CAN-pro: Computer aided nutritional analysis program for professionals; Cls: Confidence intervals; FFQ: Food frequency questionnaire;
HDL: High-density lipoprotein; HMG-CoA: 3-hydroxy-3-methylglutarylcoenzyme A; ORs: Odds ratios; SPSS: Statistical package for social science

\section{Acknowledgements}

The authors are grateful to the patients and their caregivers for their involvement in this study.

\section{Funding}

This research was supported by Basic Science Research Program through the National Research Foundation of Korea (NRF) funded by the Ministry of Education (NRF-2015R1D1A1A09060823).

\section{Availability of data and materials}

Data will not be shared. For having this data, please contact with Yongsoon Park, PhD, the supervisor of the study, at yongsoon@hanyang.ac.kr.

\section{Authors' contributions}

PY designed, supervised the study, and finalized the manuscript. KD performed the statistical analysis and revised the manuscript. LJS and KYN collected the data and wrote the first draft. JYK, LKG, and CD recruited patients and collected clinical data. All authors have read and approved the final version of this manuscript.

\section{Ethics approval and consent to participate}

This study protocol was conducted according to the guidelines laid out in the Declaration of Helsinki and approved by the Institutional Review Board of HYU (HYI-14-001-2). Written informed consent was obtained from all participants.

\section{Consent for publication}

Not applicable.

\section{Competing interests}

The authors declare that they have no competing interests.

\section{Publisher's Note}

Springer Nature remains neutral with regard to jurisdictional claims in published maps and institutional affiliations.

\section{Author details}

'Department of Food and Nutrition, Hanyang University, 222 Wangsimni-ro, Seongdong-gu, Seoul 04763, South Korea. ${ }^{2}$ Division of Hepatobiliary and Pancreas Surgery, Department of Surgery, Hanyang University College of Medicine, 222 Wangsimni-ro, Seongdong-gu, Seoul 04763, South Korea.

Received: 31 August 2017 Accepted: 15 November 2017

Published online: 23 November 2017

\section{References}

1. Yoo EH, Lee SY. The prevalence and risk factors for gallstone disease. Clin Chem Lab Med. 2009;47(7):795-807.

2. Chang YR, Jang JY, Kwon W, Park JW, Kang MJ, Ryu JK, et al. Changes in demographic features of gallstone disease: 30 years of surgically treated patients. Gut Liver. 2013;7(6):719-24.

3. Stringer MD, Fraser S, Gordon KC, Sharples K, Windsor JA. Gallstones in New Zealand: composition, risk factors and ethnic differences. ANZ J Surg. 2013; 83(7-8):575-80.

4. Gustafsson U, Sahlin S, Einarsson C. Biliary lipid composition in patients with cholesterol and pigment gallstones and gallstone-free subjects: deoxycholic acid does not contribute to formation of cholesterol gallstones. Eur J Clin Investig. 2000;30(12):1099-106

5. Maki T. Pathogenesis of calcium bilirubinate gallstone: role of E. coli, betaglucuronidase and coagulation by inorganic ions, polyelectrolytes and agitation. Ann Surg. 1966;164(1):90-100.

6. Ortega RM, Fernandez-Azuela M, Encinas-Sotillos A, Andres P, Lopez-Sobaler AM. Differences in diet and food habits between patients with gallstones and controls. J Am Coll Nutr. 1997;16(1):88-95.

7. Misciagna G, Centonze S, Leoci C, Guerra V, Cisternino AM, Ceo R, et al. Diet, physical activity, and gallstones - a population-based, case-control study in southern Italy. Am J Clin Nutr. 1999;69(1):120-6. 
8. Compagnucci AB, Perroud HA, Batalles SM, Villavicencio R, Brasca A, Berli D, et al. A nested case-control study on dietary fat consumption and the risk for gallstone disease. J Hum Nutr Diet. 2016;29(3):338-44.

9. Tsai CJ, Leitzmann MF, Willett WC, Giovannucci EL. Fruit and vegetable consumption and risk of cholecystectomy in women. Am J Med. 2006; 119(9):760-7.

10. Nordenvall C, Oskarsson V, Wolk A. Fruit and vegetable consumption and risk of cholecystectomy: a prospective cohort study of women and men. Eur J Nutr. 2016. doi:10.1007/s00394-016-1298-6.

11. Kameda H, Ishihara F, Shibata K, Tsukie E. Clinical and nutritional study on gallstone disease in Japan. Jpn J Med. 1984;23(2):109-13.

12. Tsai CJ, Leitzmann MF, Willett WC, Giovannucci EL. Long-term intake of dietary fiber and decreased risk of cholecystectomy in women. Am J Gastroentero. 2004;99(7):1364-70.

13. Jorgensen T, Jorgensen LM. Gallstones and diet in a Danish population. Scand J Gastroenterol. 1989;24(7):821-6.

14. Davidovic DB, Tomic DV, Jorg JB. Dietary habits as a risk factor of gallstone disease in Serbia. Acta Chir lugosl. 2011;58(4):41-4.

15. Shin Y, Choi D, Lee KG, Choi HS, Park Y. Association between dietary intake and postlaparoscopic cholecystectomic symptoms in patients with gallbladder disease. Korean J Intern Med. 2017. doi:https://doi.org/10.3904/ kjim.2016.223.

16. Koeth RA, Wang Z, Levison BS, Buffa JA, Org E, Sheehy BT, et al. Intestinal microbiota metabolism of L-carnitine, a nutrient in red meat, promotes atherosclerosis. Nat Med. 2013;19(5):576-85.

17. Tsai CJ, Leitzmann MF, Willett WC, Giovannucci EL. Long-term intake of trans-fatty acids and risk of gallstone disease in men. Arch Intern Med. 2005 165(9):1011-5.

18. Moerman CJ, Smeets FW, Kromhout D. Dietary risk factors for clinically diagnosed gallstones in middle-aged men. A 25-year follow-up study (the Zutphen study). Ann Epidemiol. 1994;4(3):248-54.

19. Caroli-Bosc FX, Deveau C, Peten EP, Delabre B, Zanaldi H, Hebuterne X, et al. Cholelithiasis and dietary risk factors: an epidemiologic investigation in Vidauban, Southeast France. General Practitioner's group of Vidauban. Dig Dis Sci. 1998;43(9):2131-7.

20. Jessri M, Rashidkhani B. Dietary patterns and risk of gallbladder disease: a hospital-based case-control study in adult women. J Health Popul Nutr. 2015:33(1):39-49.

21. Tseng M, DeVellis RF, Maurer KR, Khare M, Kohlmeier L, Everhart JE, et al. Food intake patterns and gallbladder disease in Mexican Americans. Public Health Nutr. 2000;3(2):233-43.

22. Conter RL, Roslyn JJ, Pitt HA, DenBesten L. Carbohydrate diet-induced calcium bilirubinate sludge and pigment gallstones in the prairie dog. J Surg Res. 1986;40(6):580-7.

23. Lee YC, Song DK, Kim JS, Choi CS. Effect of cholestyramine on the formation of pigment gallstone in high carbohydrate diet-fed hamsters. J Korean Med Sci. 1996;11(5):397-401.

24. Park YH, Park SJ, Jang JY, Ahn YJ, Park YC, Yoon YB, et al. Changing patterns of gallstone disease in Korea. World J Surg. 2004;28(2):206-10.

25. Lee SK, Sobal J. Socio-economic, dietary, activity, nutrition and body weight transitions in South Korea. Public Health Nutr. 2003:6(7):665-74.

26. Lee SY, Park HS, Kim DJ, Han JH, Kim SM, Cho GJ, et al. Appropriate waist circumference cutoff points for central obesity in Korean adults. Diabetes Res Clin Pract. 2007;75(1):72-80.

27. Korea National Health and Nutrition Examination Survey. http://knhanes.cdc. go.kr. Accessed 23 Aug 2017.

28. Garson GD. Factor analysis: statistical methods and practical issues. Soc Sci Comput Rev. 1999;17(1):129-31.

29. Willett WC, Howe GR, Kushi LH. Adjustment for total energy intake in epidemiologic studies. Am J Clin Nutr. 1997;65(suppl):1220S-8S.

30. Boden G. Free fatty acids and insulin secretion in humans. Curr Diab Rep. 2005;5(3):167-70.

31. Nakeeb A, Comuzzie AG, Al-Azzawi H, Sonnenberg GE, Kissebah AH, Pitt HA. Insulin resistance causes human gallbladder dysmotility. J Gastrointest Surg. 2006;10(7):940-9.

32. Ruhl CE, Everhart JE. Association of diabetes, serum insulin, and C-peptide with gallbladder disease. Hepatology. 2000;31(2):299-303.

33. Nepokroeff CM, Lakshmanan MR, Ness GC, Dugan RE, Porter JW. Regulation of the diurnal rhythm of rat liver beta-hydroxy-beta-methylglutaryl coenzmye a reductase activity by insulin, glucagon, cyclic AMP and hydrocortisone. Arch Biochem Biophys. 1974;160(2):387-96.
34. Dubrac S, Parquet M, Blouquit Y, Gripois D, Blouquit MF, Souidi M, et al. Insulin injections enhance cholesterol gallstone incidence by changing the biliary cholesterol saturation index and apo $\mathrm{A}-\mathrm{I}$ concentration in hamsters fed a lithogenic diet. J Hepatol. 2001;35(5):550-7.

35. Judd JT, Clevidence BA, Muesing RA, Wittes J, Sunkin ME, Podczasy JJ. Dietary trans fatty acids: effects on plasma lipids and lipoproteins of healthy men and women. Am J Clin Nutr. 1994;59(4):861-8.

36. Jonkers IJ, Smelt AH, Ledeboer M, Hollum ME, Biemond I, Kuipers F, et al. Gall bladder dysmotility: a risk factor for gall stone formation in hypertriglyceridaemia and reversal on triglyceride lowering therapy by bezafibrate and fish oil. Gut. 2003:52(1):109-15.

37. Marcus SN, Heaton KW. Intestinal transit, deoxycholic acid and the cholesterol saturation of bile—three inter-related factors. Gut. 1986;27(5): $550-8$.

38. Sichieri R, Everhart JE, Roth $\mathrm{H}$. A prospective study of hospitalization with gallstone disease among women: role of dietary factors, fasting period, and dieting. Am J Public Health. 1991;81(7):880-4.

39. Kim MH, Lim BC, Myung SJ, Lee SK, Ohrr HC, Kim YT, et al. Epidemiological study on Korean gallstone disease: a nationwide cooperative study. Dig Dis Sci. 1999:44(8):1674-83.

40. Gielkens HA, Lam WF, Coenraad M, Frolich M, van Oostayen JA, Lamers CB, et al. Effect of insulin on basal and cholecystokinin-stimulated gallbladder motility in humans. J Hepatol. 1998;28(4):595-602.

41. Leitzmann MF, Giovannucci EL, Stampfer MJ, Spiegelman D, Colditz GA Willett WC, et al. Prospective study of alcohol consumption patterns in relation to symptomatic gallstone disease in men. Alcohol Clin Exp Res. 1999;23(5):835-41.

42. Leitzmann MF, Tsai CJ, Stampfer MJ, Rimm EB, Colditz GA, Willett WC, et al. Alcohol consumption in relation to risk of cholecystectomy in women. Am J Clin Nutr. 2003;78(2):339-47.

43. Probert CS, Emmett PM, Heaton KW. Some determinants of whole-gut transit time: a population-based study. QJM. 1995;88(5):311-5.

44. Thornton J, Symes C, Heaton K. Moderate alcohol intake reduces bile cholesterol saturation and raises HDL cholesterol. Lancet. 1983;2(8354):819-22.

45. Thornton JR, Heaton KW, Macfarlane DG. A relation between high-densitylipoprotein cholesterol and bile cholesterol saturation. Brit Med J. 1981; 283(6303):1352-4

46. Saluja AK, Bhagat L. Pathophysiology of alcohol-induced pancreatic injury. Pancreas. 2003;27(4):327-31.

47. Zhang YP, Li WQ, Sun YL, Zhu RT, Wang WJ. Systematic review with metaanalysis: coffee consumption and the risk of gallstone disease. Aliment Pharmacol Ther. 2015:42(6):637-48

48. Douglas BR, Jansen JB, Tham RT, Lamers CB. Coffee stimulation of cholecystokinin release and gallbladder contraction in humans. Am J Clin Nutr. 1990;52(3):553-6.

49. Ishizuk H, Eguchi H, Oda T, Ogawa S, Nakagawa K, Honjo S, et al. Relation of coffee, green tea, and caffeine intake to gallstone disease in middle-aged Japanese men. Eur J Epidemiol. 2003;18(5):401-5.

\section{Submit your next manuscript to BioMed Central and we will help you at every step:}

- We accept pre-submission inquiries

- Our selector tool helps you to find the most relevant journal

- We provide round the clock customer support

- Convenient online submission

- Thorough peer review

- Inclusion in PubMed and all major indexing services

- Maximum visibility for your research

Submit your manuscript at www.biomedcentral.com/submit 